\title{
Toll-like receptor 8: augmentation of innate immunity in platinum resistant ovarian carcinoma
}

This article was published in the following Dove Press journal:

Clinical Pharmacology:Advances and Applications

22 May 2013

Number of times this article has been viewed

\section{Taylor J Brueseke \\ Krishnansu S Tewari \\ Department of Obstetrics and Gynecology, Division of Gynecologic Oncology, University of California, Irvine, Orange, CA, USA}

\begin{abstract}
Ovarian cancer is the most deadly gynecologic cancer, with 15,000 anticipated deaths within the United States alone in 2012, and new treatment strategies are needed. Ovarian cancer tumors are known to host an immunosuppressive microenvironment. This suppression may be reversible via activation of the innate immune response. Toll-like receptor 8 activates innate immunity while simultaneously inhibiting the effects of regulatory $\mathrm{T}$ cells within the ovarian cancer tumors. VTX-2337 is a novel small molecule ligand of Toll-like receptor 8 and is currently the subject of a Phase II randomized, double-blind, placebo-controlled trial Gynecologic Oncology Group (GOG)-3003 for patients with recurrent platinum-resistant ovarian cancer. We look forward to the results of this trial as support for the paradigm of process therapy in the treatment of ovarian cancer.
\end{abstract}

Keywords: immunotherapy, ovarian cancer, Gynecology Oncology Group partners, VTX 2237

\section{Introduction}

Ovarian cancer is the deadliest gynecological cancer, with 22,000 new cases and 15,000 deaths anticipated within the United States in 2012. ${ }^{1}$ Despite years of intense research, the etiology of this disease remains unknown. There is currently no consistent early symptom or screening test, and consequently, most patients present with advanced-stage disease. Traditional therapy for ovarian cancer has included maximal cytoreductive surgery followed by cytotoxic chemotherapy with a platinum/taxane-based regimen. While most ovarian cancer is initially chemosensitive, recurrence of the disease is common and may be categorized as either platinum-sensitive or refractory. Current treatment regimens for platinum resistant recurrence include single agent paclitaxel, liposomal doxorubicin, or topotecan. Outcomes with these regimens are poor, with significant potential toxicity, thus, new treatment modalities are needed. The Gynecologic Oncology Group (GOG) is actively pursuing alternative treatment regimens including intraperitoneal chemotherapy, dose-dense paclitaxel, and anti-angiogenesis therapy. To date, there have been four positive Phase III clinical trials demonstrating improved progression-free survival with the anti-angiogenesis monoclonal antibody bevacizumab, in patients with ovarian cancer. ${ }^{2-5}$

Additional research has focused on immunotherapy and includes: ${ }^{6}$ administration of tumor-directed antibodies, ${ }^{7,8}$ administration of immune-stimulatory cytokines, ${ }^{9,10}$ peptide cancer vaccines, adoptive cell transfers, ${ }^{11}$ depletion of regulatory $\mathrm{T}$ cells, and dysfunctional immune cosignaling blockade. Each of these has met with 
modest results. Further insights were gained with the mapping of the ovarian cancer genome atlas, ${ }^{12}$ which elucidated multiple aberrant cellular pathways within ovarian tumor cells. These discoveries have generated interest in specific pathway inhibition including: poly (adenosine diphosphate [ADP]-ribose) polymerase (PARP) inhibitors, ${ }^{13,14}$ anti-folic acid receptor inbitors, ${ }^{15}$ heat shock protein 90 inhibition, ${ }^{16}$ gamma secretase inhibitors, ${ }^{17}$ and aurora kinase inhibtors. ${ }^{18}$ However, tumors often possess multiple aberrant pathways with a high degree of cross talk between signaling cascades, and thus, therapeutics directed at pathway inhibition may not have optimal success if the complexity of the pathway is not fully recognized or if a given patient does not possess the targeted aberrant pathway.

Reversing the process of tumor-induced immunosuppression is a promising alternative in immunotherapy. Ovarian cancer tumors are known to contain tumor-infiltrating lymphocytes (including T cells and dendritic cells [DCs]). These lymphocytes, however, are quiescent and do not readily attack tumor cells. The reason for this is multifactorial; however, regulatory $\mathrm{T}$ cells and inert $\mathrm{DCs}$ are postulated to play a role in the creation of this immunosuppression. Activation of Toll-like receptors (TLRs) holds potential for the reversal of this immunosuppressive microenvironment. As mentioned in the awarding of the 2011 Nobel Prize in Medicine or Physiology, TLRs and DCs are the link between innate and adaptive immunity, ${ }^{19}$ thus, triggering the innate immune response in ovarian cancer tumors may result in activation of cytotoxic $\mathrm{T}$ cells and natural killer cells and in the elimination of ovarian cancer cells.

\section{Innate immunity}

Ralph Steinmann, Bruce Beutler, and Jules Hoffmann were awarded the 2011 Nobel Prize in Medicine or Physiology for discovering the roles that DCs and TLRs play as the gatekeepers of innate immunity. The innate immune system is the first line of defense against foreign organisms and includes natural killer cells, mast cells, eosinophils, basophils, physical barriers, and phagocytic cells, including DCs, macrophages, and neutrophils. DCs possess TLRs, which were the first pathogen-associated pattern-recognition receptors to be discovered. Activation of these receptors by exposure to foreign molecules results in the activation of a signal cascade, with multiple downstream effects. ${ }^{20}$ Upon activation, DCs increase their production of major histocompatibility complex (MHC) class II molecules and migrate to draining lymph nodes, where they present antigens to naïve T cells. The presentation of antigens via $\mathrm{MHC}$ class II molecules to T helper cells type 1 and 2 results in the activation of the adaptive immune response, with clonal expansion of $\mathrm{T}$ cells and the activation of $\mathrm{B}$ cell-mediated antibody secretion.

\section{Tumor microenvironment}

Tumor-infiltrating lymphocytes were described in the microenvironment of ovarian cancer as early as $1988 .^{21}$ The types of lymphocytes present include CD8+ T cells, macrophages, a relatively low concentration of natural killer cells, B cells, polymorphonuclear cells, and rare mast cells. ${ }^{22}$ Significantly, the presence of tumor-infiltrating lymphocytes is associated with improved overall survival. ${ }^{23,24}$ However, these lymphocytes do not actively target ovarian cancer cells. Rather, an immunosuppressive microenvironment is present within the tumor. Active evasion of the immune response involves at least two cell types: (1) CD4+ CD25+ T cells (T regulatory cells [Tregs]), and (2) CD11 c + MCH-II myeloid DCs (mDCs), which are the most abundant subset of leukocytes in the solid ovarian cancer microenvironment. ${ }^{25}$ Recent research has exploded regarding the role and function of Tregs ${ }^{6,7,24,26-32}$ and suggests that Tregs actively induce cytotoxic T cell anergy in at least two ways: (1) direct cell-tocell contact inhibition, and (2) humoral inhibition, including the downregulation of interleukin-2. The presence of Tregs has been associated with poor prognosis. In one study, individuals with the highest Treg counts per high-powered field of ovarian cancer tumor tissue had a 25 -fold higher death hazard ratio $(95 \% \text { CI 6.8-92.1) })^{33}$ compared with those with the lowest Treg cell counts, even after controlling for the stage of disease and surgical debulking. Additionally, mDCs have recently been shown to actively inhibit $\mathrm{T}$ cell antitumor activity by expressing functional levels of the immunosuppressive proteins PD-L1. ${ }^{34}$

\section{Toll-like receptors}

We believe that TLRs may hold the key to reversing this immunosuppressive microenvironment. TLRs constitute a family of highly conserved pattern-recognition receptors (see Table 1). ${ }^{35}$ Ten unique TLRs have been characterized in humans. Of these, TLRs 1, 2, 4, 5, and 6 are expressed on the cell membrane, while TLRs 3, 7, 8, and 9 are expressed within the endolysosomal compartmental pathway. ${ }^{36-38}$ TLRs detect a number of different foreign molecules including: double stranded deoxyribonucleic acid (DNA) (TLR3), lipopolysaccharides (TLR4), flagellin (TLR5), single-stranded viral ribonucleic acid (RNA) (TLR7/8), and unmethylated $\mathrm{CpG}$ sites of DNA of bacteria and viruses 
Table I Breakdown of Toll-like receptors: their cellular expression, intracellular location, natural ligands.

\begin{tabular}{|c|c|c|c|}
\hline & Cellular expression ${ }^{30,35,40,41,59}$ & Location within cell ${ }^{36-38}$ & Natural ligand ${ }^{39}$ \\
\hline TLRI & $\begin{array}{l}\text { Monocyte, mDC, } \\
\text { B cell, NK, neutrophil, } \\
\text { basophil }\end{array}$ & Cell membrane & Triacyl lipopeptide \\
\hline TLR2 & $\begin{array}{l}\text { Monocyte, mastocytes, } \\
\mathrm{mDC}\end{array}$ & Cell membrane & $\begin{array}{l}\text { Triacyl lipopeptide, lipoteichoic acid, zymosan, } \\
\text { porins, macrophage-activating lipopeptide, bacterial } \\
\text { peptidoglycan, lipoarabinomannan }\end{array}$ \\
\hline TLR3 & $\mathrm{mDC}$ & Endosomal membrane & dsDNA \\
\hline TLR4 & $\begin{array}{l}\text { Monocytes, macrophages, } \\
\text { mDC, mastocytes, basophil }\end{array}$ & Cell membrane & LPS, mannan, phospholipds, envelope proteins \\
\hline TLR5 & mDC, monocyte, NK, T cell & Cell membrane & Flagellin \\
\hline TLR6 & $\begin{array}{l}\text { Monocyte, mastocytes, } \\
\text { mDC }\end{array}$ & Cell membrane & $\begin{array}{l}\text { Triacyl lipopeptide, lipoteichoic acid, zymosan, } \\
\text { porins, macrophage-activating lipopeptide, bacterial } \\
\text { peptidoglycan, lipoarabinomannan }\end{array}$ \\
\hline TLR 7 & pDC, eosinophil & Endosomal membrane & ssRNA (viral) \\
\hline TLR8 & $\begin{array}{l}\mathrm{mDC}, \mathrm{T} \text { and } \mathrm{B} \text { cells, } \\
\text { eosinophils, monocytes }\end{array}$ & Endosomal membrane & ssRNA (viral) \\
\hline TLR9 & $\begin{array}{l}\text { pDC, B cells, basophil, } \\
\text { eosinophil }\end{array}$ & Endosomal membrane & DNA (bacterial/viral) \\
\hline TLRIO & pDC, neutrophil, B cell, basophi & ilCell membrane & Unknown \\
\hline
\end{tabular}

Abbreviations: DNA, deoxyribonucleic acid; dsDNA, double-stranded DNA; LPS, lipopolysaccharide; mDC, myeloid dendritic cells; NK, natural killer cells; pDC, plasmatoid dendritic cells; ssRNA, single stranded ribonucleic acid; TLR, Toll-like receptors.

(TLR9). ${ }^{39}$ TLRs are expressed broadly on hematopoietic cells, including DCs, plasma cells, monocytes, and B cells. ${ }^{30,35,40,41}$

TLR activation induces the expression of selectins, chemokines, and chemokine receptors, the combination of which regulates migration of inflammatory cells). ${ }^{42,43}$ As reviewed by Smits et al, ${ }^{31}$ the administration of TLR7/8 agonists results in the secretion of multiple proinflammatory Th1-type cytokines, including tumor necrosis factor (TNF)-alpha, interleukins 1, 6, and 8, interferon-inducible protein 10 , monocyte chemotactic protein 1 , interleukin $12 \mathrm{p} 40$, interleukin-12p70, and interleukin 18. The molecular pathways in TLR signaling have previously been reviewed.

TLR7 is the therapeutic target of imiquimod, which has been used successfully in the treatment of skin cancers. ${ }^{44-46}$ Given that TLR9 is expressed predominantly in B cells, it is currently being explored in clinical trials for cutaneous lymphoma ${ }^{47}$ and leukemia. ${ }^{48}$

TLR8 is unique in the TLR family: the activation of TLR8 has a direct inhibitory effect on Tregs. ${ }^{49}$ The exact mechanism for this is unknown; however, Tregs express TLR $8,{ }^{50}$ and the ability of TLR8 to reverse Treg inhibition is dendritic cell independent. ${ }^{31}$ TLR 8 also likely has direct and indirect activating effects on natural killer cells, causing them to produce interferon-gamma. ${ }^{40,51,52}$ The overall result of TLR 8 activation is robust enhancement of the innate immune response. Additionally, TLR 8 receptors have been demonstrated to have variable expression within epithelial ovarian cancer tumors. ${ }^{53}$

\section{VTX-2337}

The unique ability of TLR8 to reverse Treg immunosuppression and augment immunity in the tumor microenvironment makes it an ideal target for ovarian cancer therapy. VTX-2337 is a synthetic small-molecule agonist that is specific to TLR8, with a molecular weight of 458.6 Daltons and a molecular structure based on a 2-aminobenzazepine core. A recently published in vitro study ${ }^{40}$ using TLR-transfected human embryonic kidney cells showed that VTX-2337 selectively activates TLR8. The same study showed that VTX-2337 has the ability to augment the immune response on multiple levels (Figure 1): it induces mDCs and monocytes to produce high levels of interleukin-12 and TNF-alpha. It directly stimulates natural killer cells to produce interferon-gamma and increases their lytic activity. Furthermore, VTX-2337 augments antibody-dependent cell-mediated cytotoxity. This process works synergistically with standard chemotherapy. Contrary to the traditionally immunosuppressive effects of most systemic cytotoxic chemotherapy, doxorubicin has been reported to increase the tumor cell surface exposure of calreticulin and the internalization of tumor cell antigens by phagocytic DCs. ${ }^{54,55}$ Furthermore, dying cancer cells have been shown to release high-mobility group box 1 protein, a ligand for TLR4 that has been reported to synergize with TLR8 to activate DCs and prime T-cell response. ${ }^{40}$ Therefore, 


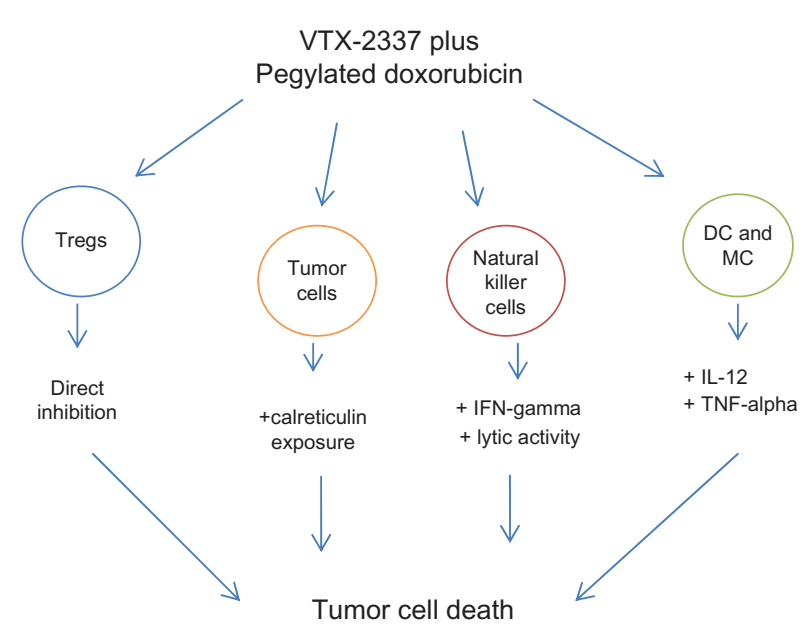

Figure I Schema of some of the hypothesized effects of the administration of VTX2337 and pegylated doxorubicin resulting in the activation of multiple components of innate immunity, including immunosuppressive regulatory $T$ cells (Tregs), tumor cellsnatural killer cells (NK), dendritic cells (DC), and monocytes (MC), and the secretion of multiple cytokines.

Notes: These changes in the microenvironment may lead to increased tumor cell death. Abbreviations: IFN, interferon; IL, interleukin; TNF, tumor necrosis factor.

VTX-2337 has the potential to induce robust activation of the innate and adaptive immune response.

A Phase I clinical trial (NTC00688415), sponsored by VentiRx Pharmaceuticals (Seattle, WA, USA), found VTX-2337 to be well tolerated and to have dose-dependent pharmacologic activity. ${ }^{56}$ As presented by Cohen et a ${ }^{56}$ at the American Society of Clinical Oncology (ASCO) 2011 meeting, the inclusion criteria for this study were: (1) locally advanced or metastatic solid tumors or lymphoma, and (2) Eastern Cooperative Oncology Group (ECOG) performance status of $0-1$. The exclusion criteria were: (1) anticancer therapy within 2 weeks, (2) immunosuppressive therapy within 2 weeks, and (3) active autoimmune disease. In this study, VTX-2337 was administered to 33 patients with advanced solid tumors (the most common histologies were colorectal cancer, pancreatic cancer, and melanoma), using a modified Fibonacci dose escalation scheme. Eight cohorts of 3-8 patients received doses from $0.1 \mathrm{mg} / \mathrm{m}^{2}$ to $3.8 \mathrm{mg} /$ $\mathrm{m}^{2}$. The median age of the patients was 65 years. There was an average of 3.1 years between the time of diagnosis and study entry. The most common drug-related adverse events were grade 1-2 injection site reaction (85\%), chills (58\%), fever (42\%), and flu-like symptoms (24\%). Grade 3 hypotension occurred in 1/6 patients and was the only dose-limiting toxicity. The primary outcome measures were safety and the identification of dose-limiting toxicities and pharmacokinetics. The secondary outcome measures were the identification of pharmacodynamics and mean toxic dose. The results showed that the plasma levels of multiple immune mediators (including granulocyte colony-stimulating factor [G-CSF], monocyte chemotactic protein [MCP]1, macrophage inflammatory protein [MIP]1-beta, and TNF-alpha) were increased. As measured by the Response Evaluation Criteria in Solid Tumors (RECIST) criteria, 25\% of patients demonstrated disease stabilization at 8 weeks.

\section{VTX-2337 and ovarian cancer}

Two clinical trials are currently investigating VTX-2337 in patients with ovarian cancer. GOG-9925 (study chair BJ Monk) is a Phase I trial undergone in collaboration with the National Cancer Institute, NCT01294293, ${ }^{57}$ evaluating the side-effect profile and best dose of VTX-2337 and liposomal doxorubicin, in patients with persistent or recurrent ovarian epithelial, fallopian tube, or peritoneal cancer. The primary outcomes are first-cycle dose-limiting toxicity and the frequency/severity of toxicities. The secondary outcome measures are immune activation and identification of the pharmacokinetics of VTX-2337 and pegylated liposomal doxorubicin. Enrollment criteria include measurable disease by RECIST 1.1, or detectable disease by CA-125 measurement, or other solid abnormalities on radiographic imaging. Enrolled patients have one prior platinum-based chemotherapeutic regimen and recurrence of disease within a 12-month platinum-free interval and do not have evidence of central nervous system (CNS) metastasis. This multicenter, doseescalating study enrolled patients from April 2011 to June $2012 .{ }^{57}$ No results have yet been published from this trial.

A Phase II randomized, double-blind, placebo-controlled study is also now underway. Known as GOG Partners-3003 (study chair BJ Monk), NCT01666444 this trial is sponsored by VentiRx Pharmaceuticals in collaboration with the GOG partners and enrolls patients with recurrent or persistent platinumresistant epithelial ovarian, fallopian tube, or primary peritoneal carcinoma, with measurable disease by RECIST 1.1 criteria and at least one target lesion. Figure 2 shows a schema of the trial structure: the investigational arm is VTX-2337 plus standard regimen pegylated liposomal doxorubicin (PLD). The reference arm is placebo plus standard regimen PLD. Patients who have previously been treated with VTX-2337, doxorubicin, PLD, or other anthracycline, patients receiving immunosuppressive therapy for any reason, and patients with active autoimmune disease are excluded from this study. $3.0 \mathrm{mg} / \mathrm{m}^{2}$ of VTX-2337 or placebo will be administered as a subcutaneous injection on days 3,10 , and 17 of the first four 28-day treatment cycles and thereafter, on cycle day 3 only. The primary outcome will be overall survival, with a planned analysis to occur approximately 15 months after the last patient is enrolled. Secondary outcomes 


\section{GOG-3003}

Patients with recurrent or resistant epithelial ovarian, fallopian tube or primary peritoneal carcinoma with measurable disease by Response Evaluation Criteria In Solid Tumors (RECIST) 1.1

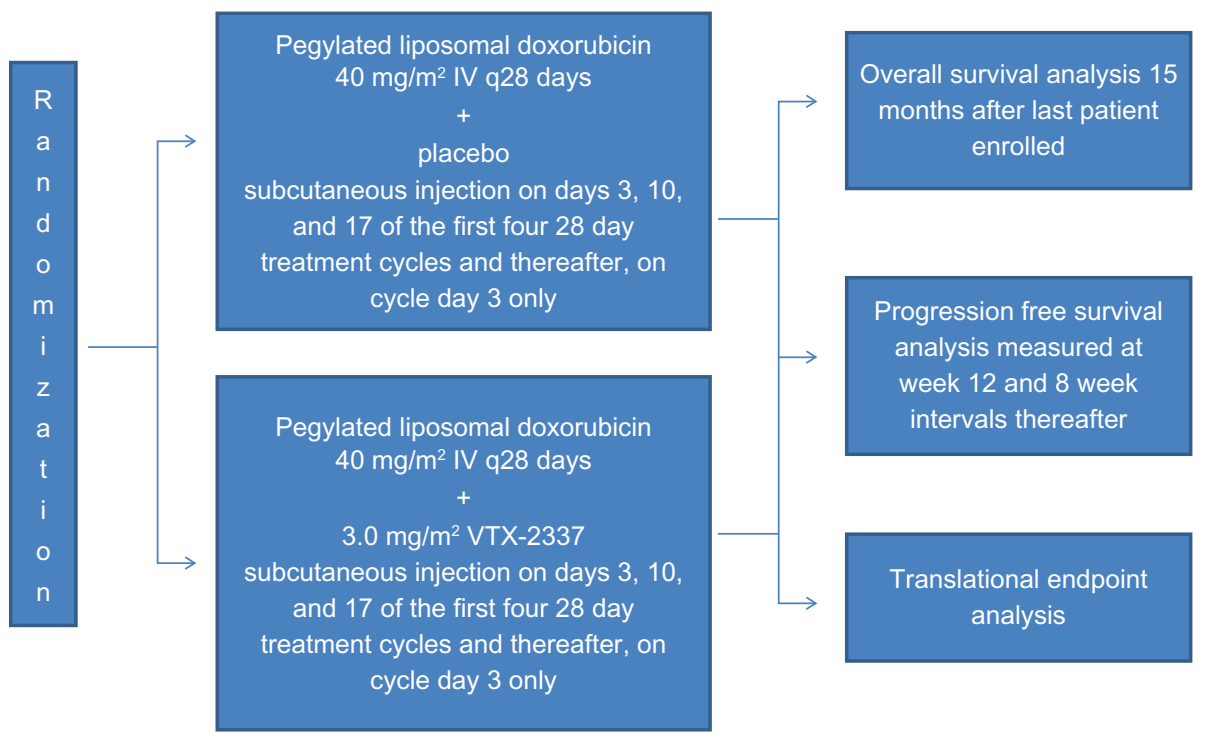

Figure 2 Schema of Gynecologic Oncology Group (GOG) partners trial 3003.

Notes: Response Evaluation Criteria in Solid Tumors (RECIST) ${ }^{60}$

Abbreviations: IV, intravenous; q, every.

will be the frequency and nature of side-effects of VTX-2337 and progression-free survival using Immune Related Response Evaluation Criteria in Solid Tumors. CA-125 measurements will be required to be normal for diagnosis of complete response. Progression will be assessed at week 12 and at 8-week intervals thereafter. Exploratory objectives include the assessment of the effect of TLR8 polymorphisms and immune cell subsets (as measured by immunohistochemistry in primary tumor tissue) on clinical outcomes, such as overall survival, progression-free survival, and overall response rate. ${ }^{58}$

\section{Conclusion}

In conclusion, ovarian cancer remains a deadly disease, and new therapeutic approaches are needed. The immunosuppressive microenvironment present in ovarian tumors represents a pathologic process that is a prime target for novel therapies. Indeed, the 2011 Nobel Prize in Medicine or Physiology highlights that TLRs are the gateway to activating the innate immune response, and it appears that TLR 8 ligands are in a unique position to augment the current treatment of patients with ovarian cancer. Novel immunotherapeutic strategies and manipulation of the micro-enviroment may hold the key to future success in ovarian cancer therapy.

\section{Disclosure}

The authors report no conflicts of interest in this work.

\section{References}

1. Siegel R, Naishadham D, Jemal A. Cancer statistics, 2012. CA Cancer J Clin. 2012;62(1):10-29.

2. Perren TJ, Swart AM, Pfisterer J, et al; ICON7 Investigators. A phase 3 trial of bevacizumab in ovarian cancer. N Engl J Med. 2011;365(26): 2484-2496.

3. Burger RA, Brady MF, Bookman MA, et al; Gynecologic Oncology Group. Incorporation of bevacizumab in the primary treatment of ovarian cancer. New Engl J Med. 2011;365(26):2473-2483.

4. Pujade-Lauraine E, Hilpert F, Weber B, et al;AURELIA Investigators. AURELIA: a randomized phase III trial evaluating bevacizumab (BEV) plus chemotherapy (CT) for platinum (PT)-resistant recurrent ovarian cancer (OC). J Clin Oncol. 2012;30(Supplement 18). Available from: http://meeting. ascopubs.org/cgi/content/abstract/30/18_suppl/LBA5002?sid=799bb0463aad-4937-a1ff-10b69d3f9782. Accessed March 13, 2013.

5. Aghajanian C, Blank SV, Goff BA, et al. OCEANS: a randomized, double-blind, placebo-controlled phase III trial of chemotherapy with or without bevacizumab in patients with platinum-sensitive recurrent epithelial ovarian, primary peritoneal, or fallopian tube cancer. $J$ Clin Oncol. 2012;30(17):2039-2045.

6. Thibodeaux SR, Curiel TJ. Immune therapy for ovarian cancer: promise and pitfalls. Int Rev Immunol. 2011;30(2-3):102-119.

7. Hodi FS, Butler M, Oble DA, et al. Immunologic and clinical effects of antibody blockade of cytotoxic $\mathrm{T}$ lymphocyte-associated antigen 4 in previously vaccinated cancer patients. Proc Natl Acad Sci U SA. 2008;105(8):3005-3010.

8. Hodi FS, Mihm MC, Soiffer RJ, et al. Biologic activity of cytotoxic $\mathrm{T}$ lymphocyte-associated antigen 4 antibody blockade in previously vaccinated metastatic melanoma and ovarian carcinoma patients. Proc Natl Acad Sci U S A. 2003;100(8):4712-4717.

9. Edwards RP, Gooding W, Lembersky BC, et al. Comparison of toxicity and survival following intraperitoneal recombinant interleukin-2 for persistent ovarian cancer after platinum: twenty-four-hour versus 7-day infusion. J Clin Oncol. 1997;15(11):3399-3407.

10. Vlad AM, Budiu RA, Lenzner DE, et al. A phase II trial of intraperitoneal interleukin-2 in patients with platinum-resistant or platinum-refractory ovarian cancer. Cancer Immunol Immunother. 2010;59(2):293-301. 
11. Rosenberg SA, Dudley ME. Adoptive cell therapy for the treatment of patients with metastatic melanoma. Curr Opin Immunol. 2009; 21(2):233-240.

12. Cancer Genome Atlas Research Network. Integrated genomic analyses of ovarian carcinoma. Nature. 2011;474(7353):609-615.

13. Heitz F, Harter P, Ewald-Riegler N, Papsdorf M, Kommoss S, du Bois A. Poly(ADP-ribosyl)ation polymerases: mechanism and new target of anticancer therapy. Expert Rev Anticancer Ther. 2010;10(7): 1125-1136.

14. Ratner ES, Sartorelli AC, Lin ZP. Poly (ADP-ribose) polymerase inhibitors: on the horizon of tailored and personalized therapies for epithelial ovarian cancer. Curr Opin Oncol. 2012;24(5):564-571.

15. Naumann RW, Symanowski JT, Ghamande SA, et al. PRECEDENT: a randomized phase II trial comparing EC145 and pegylated liposomal doxorubicin (PLD) in combination, versus PLD alone, in subjects with platinum-resistant ovarian cancer. J Clin Oncol. 2010;28(Supplement 18). Available from: http://meeting.ascopubs.org/cgi/content/abstract/28/18_ suppl/LBA5012b. Accessed March 13, 2013.

16. Stecklein SR, Kumaraswamy E, Behbod F, et al. BRCA1 and HSP90 cooperate in homologous and non-homologous DNA double-strandbreak repair and G2/M checkpoint activation. Proc Natl Acad Sci USA. 2012;109(34):13650-13655.

17. Diaz-Padilla I, Clarke B, Hirte H, et al. A phase II study of RO4929097 (RO), a gamma-secretase inhibitor, in advanced platinum (Pt)resistant (R) ovarian cancer (OC): a study of the $\mathrm{PMH}$, Chicago, and California phase II consortia. J Clin Oncol. 2012;30 Suppl. Available from: https://meetinglibrary.asco.org/content/94913-114. Accessed March 13, 2013.

18. Falchook GS, Goff BA, Kurzrock R, et al. Phase I/II study of weekly paclitaxel with or without MLN8237 (alisertib), an investigational aurora A kinase inhibitor, in patients with recurrent epithelial ovarian, fallopian tube, or primary peritoneal cancer $(\mathrm{OC})$, or breast cancer $(\mathrm{BrC})$ : phase I results. J Clin Oncol. 2012;30 Suppl. Available from: http://meetinglibrary.asco.org/content/96468-114. Accessed March 13, 2013.

19. Wagner H. Innate immunity's path to the Nobel Prize 2011 and beyond. Eur J Immunol. 2012;42(5):1089-1092.

20. Janeway CA Jr, Medzhitov R. Innate immune recognition. Annu Rev Immunol. 2002;20:197-216.

21. Heo DS, Whiteside TL, Kanbour A, Herberman RB. Lymphocytes infiltrating human ovarian tumors. I. Role of Leu-19 (NKH1)-positive recombinant IL-2-activated cultures of lymphocytes infiltrating human ovarian tumors. J Immunol. 1988;140(11):4042-4049.

22. Negus RP, Stamp GW, Hadley J, Balkwill FR. Quantitative assessment of the leukocyte infiltrate in ovarian cancer and its relationship to the expression of C-C chemokines. Am J Pathol. 1997;150(5): 1723-1734.

23. Zhang L, Conejo-Garcia JR, Katsaros D, et al. Intratumoral T cells, recurrence, and survival in epithelial ovarian cancer. $N$ Engl J Med. 2003;348(3):203-213.

24. Sato E, Olson SH, Ahn J, et al. Intraepithelial CD8+ tumor-infiltrating lymphocytes and a high $\mathrm{CD} 8+$ /regulatory $\mathrm{T}$ cell ratio are associated with favorable prognosis in ovarian cancer. Proc Natl Acad Sci USA. 2005;102(51):18538-18543.

25. Scarlett UK, Cubillos-Ruiz JR, Nesbeth YC, et al. In situ stimulation of CD40 and Toll-like receptor 3 transforms ovarian cancer-infiltrating dendritic cells from immunosuppressive to immunostimulatory cells. Cancer Res. 2009;69(18):7329-7337.

26. Conrad C, Gregorio J, Wang YH, et al. Plasmacytoid dendritic cells promote immunosuppression in ovarian cancer via ICOS costimulation of Foxp3(+) T-regulatory cells. Cancer Res. 2012;72(20):5240-5249.

27. Fialová A, Partlová S, Sojka L, et al. Dynamics of T-cell infiltration during the course of ovarian cancer: the gradual shift from a Th17 effector cell response to a predominant infiltration by regulatory T-cells. Int $J$ Cancer. 2013;132(5):1070-1090.

28. Le DT, Jaffee EM. Regulatory T-cell modulation using cyclophosphamide in vaccine approaches: a current perspective. Cancer Res. 2012;72(14):3439-3444.
29. Herber DL, Nagaraj S, Djeu JY, Gabrilovich DI. Mechanism and therapeutic reversal of immune suppression in cancer. Cancer Res. 2007;67(11):5067-5069.

30. Wang D, Precopio M, Lan T, et al. Antitumor activity and immune response induction of a dual agonist of Toll-like receptors 7 and $8 . \mathrm{Mol}$ Cancer Ther. 2010;9(6):1788-1797.

31. Smits EL, Ponsaerts P, Berneman ZN, Van Tendeloo VF. The use of TLR7 and TLR8 ligands for the enhancement of cancer immunotherapy. Oncologist. 2008;13(8):859-875.

32. Kawai T, Akira S. TLR signaling. Semin Immunol. 2007;19(1):24-32.

33. Curiel TJ, Coukos G, Zou L, et al. Specific recruitment of regulatory $\mathrm{T}$ cells in ovarian carcinoma fosters immune privilege and predicts reduced survival. Nat Med. 2004;10(9):942-949.

34. Curiel TJ, Wei S, Dong H, et al. Blockade of B7-H1 improves myeloid dendritic cell-mediated antitumor immunity. Nat Med. 2003;9(5):562-567.

35. Kawai T, Akira S. The role of pattern-recognition receptors in innate immunity: update on Toll-like receptors. Nat Immunol. 2010;11(5): 373-384.

36. Heil F, Hemmi H, Hochrein H, et al. Species-specific recognition of single-stranded RNA via toll-like receptor 7 and 8. Science. 2004; 303(5663):1526-1529.

37. Lund JM, Alexopoulou L, Sato A, et al. Recognition of single-stranded RNA viruses by Toll-like receptor 7. Proc Natl Acad Sci U S A. 2004; 101(15):5598-5603.

38. Agrawal S, Kandimalla ER. Synthetic agonists of Toll-like receptors 7, 8 and 9. Biochem Soc Trans. 2007;35(Pt 6):1461-1467.

39. Kanzler H, Barrat FJ, Hessel EM, Coffman RL. Therapeutic targeting of innate immunity with Toll-like receptor agonists and antagonists. Nat Med. 2007;13(5):552-559.

40. Lu H, Dietsch GN, Matthews MA, et al. VTX-2337 is a novel TLR8 agonist that activates NK cells and augments ADCC. Clin Cancer Res. 2012;18(2):499-509.

41. Diebold SS. Recognition of viral single-stranded RNA by Toll-like receptors. Adv Drug Deliv Rev. 2008;60(7):813-823.

42. Iwasaki A, Medzhitov R. Toll-like receptor control of the adaptive immune responses. Nat Immunol. 2004;5(10):987-995.

43. Huang Q, Liu D, Majewski P, et al. The plasticity of dendritic cell responses to pathogens and their components. Science. 2001;294(5543): $870-875$.

44. Wolf IH, Smolle J, Binder B, Cerroni L, Richtig E, Kerl H. Topical imiquimod in the treatment of metastatic melanoma to skin. Arch Dermatol. 2003;139(3):273-276.

45. Majewski S, Marczak M, Mlynarczyk B, Benninghoff B, Jablonska S. Imiquimod is a strong inhibitor of tumor cell-induced angiogenesis. Int J Dermatol. 2005;44(1):14-19.

46. Korman N, Moy R, Ling M, et al. Dosing with 5\% imiquimod cream 3 times per week for the treatment of actinic keratosis: results of two phase 3, randomized, double-blind, parallel-group, vehicle-controlled trials. Arch Dermatol. 2005;141(4):467-473.

47. Kim YH, Girardi M, Duvic M, et al. Phase I trial of a Toll-like receptor 9 agonist, PF-3512676 (CPG 7909), in patients with treatment-refractory, cutaneous T-cell lymphoma. J Am Acad Dermatol. 2010;63(6):975-983.

48. Zent CS, Smith BJ, Ballas ZK, et al. Phase I clinical trial of CpG oligonucleotide 7909 (PF-03512676) in patients with previously treated chronic lymphocytic leukemia. Leuk Lymphoma. 2012;53(2):211-217.

49. Peng G, Guo Z, Kiniwa Y, et al. Toll-like receptor 8-mediated reversal of CD4+ regulatory T cell function. Science. 2005;309(5739):1380-1384.

50. Akira S, Uematsu S, Takeuchi O. Pathogen recognition and innate immunity. Cell. 2006;124(4):783-801.

51. Gorski KS, Waller EL, Bjornton-Severson J, et al. Distinct indirect pathways govern human NK-cell activation by TLR-7 and TLR-8 agonists. Int Immunol. 2006;18(7):1115-1126.

52. Hamm S, Rath S, Michel S, Baumgartner R. Cancer immunotherapeutic potential of novel small molecule TLR7 and TLR8 agonists. J Immunotoxicol. 2009;6(4):257-265. 
53. Zhou M, McFarland-Mancini MM, Funk HM, Husseinzadeh N, Mounajjed T, Drew AF. Toll-like receptor expression in normal ovary and ovarian tumors. Cancer Immunol Immunother. 2009;58(9):1375-1385.

54. Casares N, Pequignot MO, Tesniere A, et al. Caspase-dependent immunogenicity of doxorubicin-induced tumor cell death. J Exp Med. 2005;202(12):1691-1701.

55. Obeid M, Tesniere A, Ghiringhelli F, et al. Calreticulin exposure dictates the immunogenicity of cancer cell death. Nat Med. 2007;13(1): 54-61.

56. Cohen PA, Northfelt DW, Weiss GJ, et al. Phase I clinical trial of VTX2337, a selective toll-like receptor 8 (TLR8) agonist, in patients with advanced solid tumors. J Clin Oncol. 2011;29(Suppl 15). Available from: http://meeting.ascopubs.org/cgi/content/short/29/15_suppl/2537?rss=1. Accessed March 13, 2013.
57. Clinical Oncology Group. A phase I study of VTX-2337 (IND \#78,416) in combination with Doxil ${ }^{\circledR}$ (NSC\# 712227) in patients with recurrent or persistent epithelial ovarian, fallopian tube or primary peritoneal cancer. In: ClinicalTrials.gov [website on the Internet]. Bethesda, MD: US National Library of Medicine; 2011 [updated June 15, 2012]. Available from: http://clinicaltrials.gov/show/NCT01294293. NLM identifier: NCT01294293. Accessed March 13, 2013.

58. Clinical Oncology Group. A randomized, double-blind, placebocontrolled phase II Study of VTX-2337 in combination with pegylated liposomal doxorubicin (PLD) in patients with recurrent or persistent epithelial ovarian, fallopian tube or primary peritoneal cancer. In: ClinicalTrials.gov [website on the Internet]. Bethesda, MD: US National Library of Medicine; 2012 [updated March 7, 2013]. Available from: http://clinicaltrials.gov/show/NCT01666444. NLM identifier: NCT01666444. Accessed March 13, 2013.

\section{Publish your work in this journal}

Clinical Pharmacology: Advances and Applications is an international, peer-reviewed, open access journal publishing original research, reports, reviews and commentaries on all areas of drug experience in humans. The manuscript management system is completely online and includes a very quick and fair peer-review system, which is all easy to use.
Visit http://www.dovepress.com/testimonials.php to read real quotes from published authors. 